\title{
Parenting stress during infancy is a risk factor for mental health problems in 3- year-old children
}

\author{
Nayantara Hattangadi ${ }^{1}$, Katherine T. Cost $^{1}$, Catherine S. Birken ${ }^{2,3,4,5,6}$, Cornelia M. Borkhoff ${ }^{2,3,5,7}$, \\ Jonathon L. Maguire $e^{4,5,6,8,9}$, Peter Szatmari, ${ }^{1,10,11}$ and Alice Charach ${ }^{1,10^{*}}$ (D)
}

\begin{abstract}
Background: Although research on the relationship between parent and child mental health is growing, the impact of early parenting stress on preschool-aged children's mental health remains unclear. The objective was to evaluate the association between parenting stress during infancy and mental health problems in 3-year-old children.

Methods: A prospective cohort study of healthy preschool-aged children recruited from 9 primary care practices in Toronto, Canada was conducted through the TARGet Kids! primary care practice-based research network. Parenting stress was measured when children were between 0 to 16 months of age, using the Parent Stress Index Short Form, PSI-SF. Parent-reported child mental health problems were measured at 36 to 47 months using the preschool Strengths and Difficulties Questionnaire, total difficulties score (TDS). Hierarchical linear regression analysis was used to investigate the association between standardized PSI-SF and TDS, adjusted for child age, sex, temperament, sleep duration and household income. To strengthen clinical interpretation, analysis was repeated using adjusted multivariable logistic regression (TDS dichotomized at top 20\%).
\end{abstract}

Results: A total of 148 children (mean \pm SD age, $37.2 \pm 1.7$ months, 49\% male) were included in the analysis. Parenting stress during infancy (11.4 \pm 3.1 months of age) was significantly associated with mental health problems in 3-year-old children $(\beta=0.35 ; 95 \% \mathrm{Cl}=0.20-0.49, p<0.001)$. Higher parenting stress was also associated with increased odds of higher TDS $(\mathrm{OR}=2.26,95 \% \mathrm{Cl}=1.69-2.83, p<0.01)$.

Conclusion: Healthy preschool-aged children with parents reporting parenting stress during infancy had a 2 times higher odds of mental health problems at 3 years.

Keywords: Parenting stress, Child mental health, Prospective cohort, Mental health, Parent-child relationship

\section{Background}

The etiology of mental health problems in young children has garnered growing research and clinical interest (1). Early childhood is a period marked by critical emotional, social and behavioral development; in the early years, mental health problems can manifest as internalizing behaviors

\footnotetext{
* Correspondence: alice.charach@sickkids.ca

'Department of Psychiatry, Hospital for Sick Children, Toronto, ON, Canada

${ }^{10}$ Department of Psychiatry, University of Toronto, Toronto, ON, Canada

Full list of author information is available at the end of the article
}

such as fearfulness and social withdrawal, and externalizing behaviors such as irritability, temper outbursts and oppositional, non-compliant behavior $(2,3)$. Young children with such concerns continue to have difficulties as they grow older; over time, these difficulties are associated with poor academic, employment and health trajectories $(4,5)$.

Our understanding of early modifiable risk factors for mental health problems in preschool-aged children is incomplete. In older children, parenting stress has been reported as a risk factor for parent and child psychopathology

C C The Author(s). 2020 Open Access This article is licensed under a Creative Commons Attribution 4.0 International License, which permits use, sharing, adaptation, distribution and reproduction in any medium or format, as long as you give appropriate credit to the original author(s) and the source, provide a link to the Creative Commons licence, and indicate if changes were made. The images or other third party material in this article are included in the article's Creative Commons licence, unless indicated otherwise in a credit line to the material. If material is not included in the article's Creative Commons licence and your intended use is not permitted by statutory regulation or exceeds the permitted use, you will need to obtain permission directly from the copyright holder. To view a copy of this licence, visit http://creativecommons.org/licenses/by/4.0/. The Creative Commons Public Domain Dedication waiver (http://creativecommons.org/publicdomain/zero/1.0/) applies to the data made available in this article, unless otherwise stated in a credit line to the data. 
$(6,7)$. Although the literature is limited, some studies have explored the impact of parenting stress in children under 10 years of age and have found links with child behavior problems $(8,9)$. However, previous studies focused on parenting stress in the context of children with neurodevelopmental difficulties, chronic illnesses, or developmental delays $(10,11)$. Thus, the impact of early parenting stress on typically developing preschool-aged children is unclear.

There are confounding factors that impact the relationship between parenting stress and mental health problems in preschool-aged children that should be considered. Namely, temperament or biologically-based differences in child behavior patterns, have been identified as early risk factors of mental health problems in children $(12,13)$. In particular, high negative affect, evidenced as irritability, and low effortful control or poor impulse self-control, have been linked to subsequent diagnoses of Attention Deficit Hyperactivity Disorder (ADHD), Oppositional Defiant Disorder (ODD), anxiety disorders and depression $(14,15)$. As well, children who have high scores on inhibition are at a greater risk of anxiety disorders than those with lower scores on this temperamental domain (14). Moreover, there is increasing interest in the relationship between sleep and mental health in this age group $(16,17)$. Some studies link child sleep problems, bedtime resistance, and parental perceptions of child's sleep as problematic, with higher parenting stress (18).

The relationship between parenting stress in infancy and development of mental health problems in preschoolaged children is understudied. Parenting stress is a potentially modifiable factor that may contribute to mental health problems in young children. Findings could lead to including regular assessments of parenting stress as part of developmental assessments for children, thereby informing practitioners to assist parents with managing and alleviating parenting stress, and to identify and support children at higher risk for mental health problems.

The objective of our study was to evaluate the association between early parenting stress and mental health problems in preschool-aged children.

\section{Methods \\ Participants}

We conducted a prospective study of healthy urban children recruited during health supervision visits from primary care practices participating in The Applied Research Group for Kids! (TARGetKids!), a community-based research network in Toronto, Canada (www.targetkids.ca) (19). Trained research assistants administer parents/caregivers standardized questionnaires to collect information on child and parental health (19). In 2016, the preschool Strengths and Difficulties Questionnaire (P-SDQ), a brief parent-report screening measure identifying internalizing and externalizing behaviors in young children was added to the TARGet Kids! study protocol (20).

Children were included in this study if their parent/caregiver completed the measure of parenting stress (Parent Stress Index Short Form; PSI-SF) during infancy (baseline, between 0 to 16 months of age), as well as the P-SDQ during the 3 year health supervision visit (outcome, between 36 to 47 months of age). In addition, parent report of 24-h sleep duration and temperament (Child Behavior Questionnaire, Very Short Form; CBQ-VSF), collected during the 3 year health supervision visit, were also required for inclusion in this study. TARGet Kids! exclusion criteria are: $<32$ weeks gestational age; health conditions affecting growth (e.g. cystic fibrosis); chronic conditions (other than asthma and high functioning autism); severe developmental delay; unscheduled visit because of acute illness; and families who are unable to complete the measures in English (19). A total of 149 children met the inclusion criteria for this study (Fig. 1). One participant had $>20 \%$ of missing responses and was excluded, leaving $n=148$ for analysis.

Informed written consent was obtained by parents, and ethical approval was granted from the Research Ethics Boards at The Hospital for Sick Children and St. Michael's Hospital, Toronto, Canada. The cohort study is registered at www.clinicaltrials.gov (identifier NCT01869530).

\section{Exposure variable: parenting stress}

PSI-SF is a valid and reliable parent-report measure for early identification of parent-child systems under excessive stress (21). It has 36 -items, representing three domains: parent distress, parent-child dysfunctional interaction, and difficult child. Parenting stress scores, based upon all three domains, range from 36 to 180 . Parenting stress percentile scores that fall between 15 and 80 are considered typical; over 80th percentile is high. The parenting stress score has excellent internal consistency in our sample (Cronbach's alpha: 0.95).

\section{Outcome variables: mental health problems}

The P-SDQ is a 25 -item parent-report measure used to identify young children at high risk for mental health disorders. The P-SDQ has good psychometric properties and is valid for use with children age $2-4$ years (22). It is divided into five subscales (emotional problems, conduct problems, hyperactivity/inattention, peer problems and prosocial behavior), each comprising of five items rated on a 3-point Likert scale (0-2), with scores ranging from 0 to 10 . The total difficulties score (TDS) includes all subscale scores except the prosocial behavior subscale, and ranges from 0 to 40 . In our sample, the total difficulties score has acceptable internal consistency (Cronbach's alpha: 0.70). The total difficulties score can be dichotomized as being at risk of clinical problems (TDS $\geq 12$ ) or not at risk $(<12)$. Cutoff was determined based 


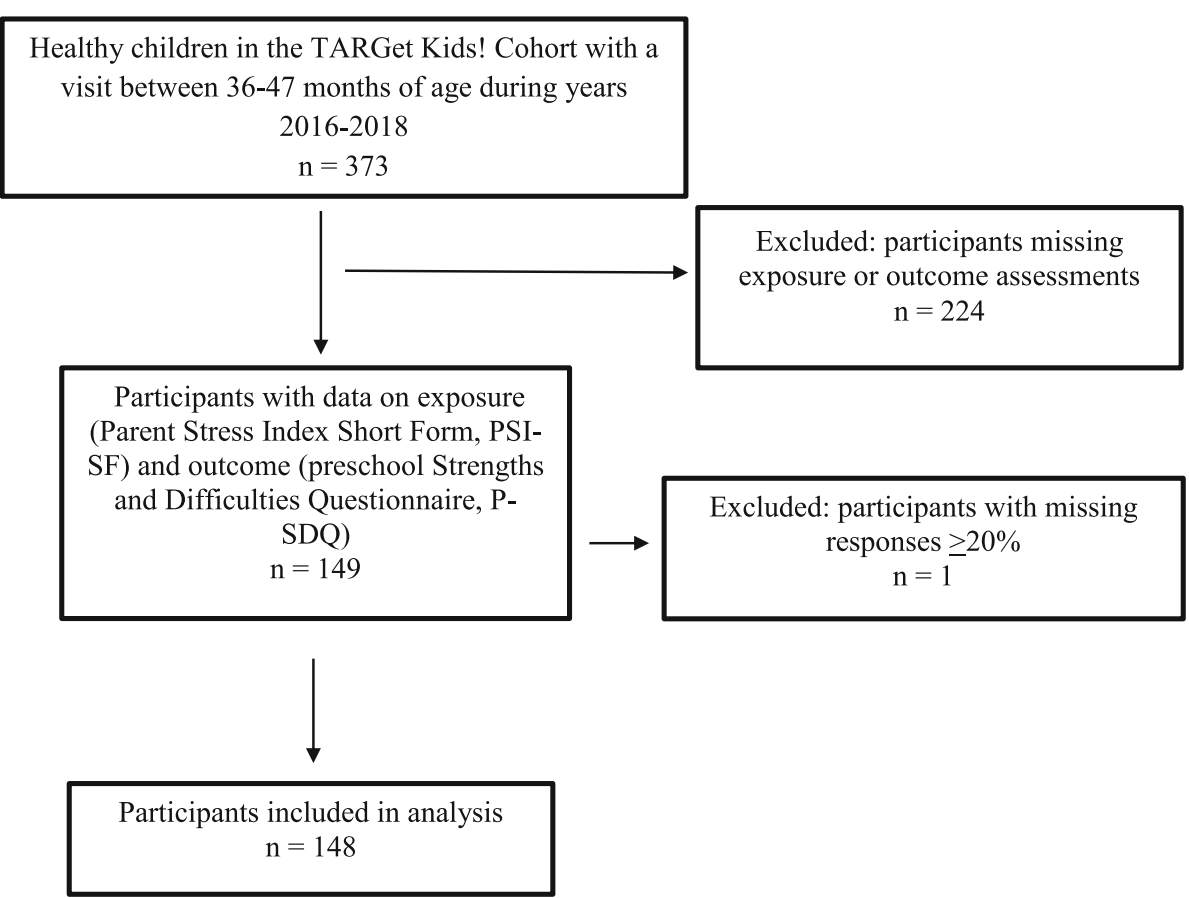

Fig. 1 Participant flowchart 1

on published norms and measures for borderline and definite clinical risk, as well as identifying scores for the top 20\% (characterized as being at risk of clinical problems) in our total sample of 3-year-old children $(23,24)$.

\section{Covariates}

An a priori literature search was conducted to identify potential confounds in the relationship between early parenting stress and mental health problems in preschool-aged children. Covariates identified included age at baseline, sex, temperament, sleep duration, and household income. Parent-reported temperament was measured using the CBQ-VSF (25). CBQ-VSF is a valid and reliable scale that identifies three domains: negative affect (negative emotional reactions), effortful control (self-control) and surgency/extraversion (motor activity and seeking closeness with others). We included the negative affect and effortful control temperament domains as confounders, as there is substantial literature in support of their impact on emotional and behavioral problems in young children (13-15). In our sample, negative affect and effortful control have acceptable internal consistency (Cronbach's alpha: 0.75 and 0.69 , respectively). Twenty-four hour sleep duration was reported by parents in response to the question "How many hours does your child usually spend sleeping in a 24-hour period"? Sleep duration was parameterized as a continuous variable denoting the number of hours slept in a 24-h period. Child age and sex, and self-report annual household income, were collected during enrollment.

\section{Sample size}

The sample size calculation for this study was based on a review of the existing literature on parenting stress and mental health problems in young children. A study with a small effect size $(r=0.1)$ and a power of $80 \%$ would require a minimum sample of 128 , to detect an association at an alpha level of 5\% (26). Thus, our sample of 148 was deemed appropriate.

\section{Statistical analysis}

Descriptive statistics were calculated for the exposure, outcomes, and covariates and presented as mean values (standard deviations) for continuous data, and percentages for categorical data. A correlation matrix was conducted to assess the Pearson correlations between key variables in this study. Hierarchical linear regression analysis was conducted to examine the association between early parenting stress and mental health problems, using a three stepapproach: 1) with covariates (model 1); 2) including key temperament variables (model 2); and 3), adding parenting stress (model 3). In addition, we used adjusted multivariable logistic regression analysis to strengthen clinical interpretation of the relationship between our exposure and outcome variable (total difficulties score dichotomized at top $20 \%$ ). All variables were standardized to interpret logistic regressions as 1 standard deviation change. Covariates specified a priori (age at baseline, sex, negative affect, effortful control, sleep duration, and household income) were included in the adjusted multivariable models. Statistical 
analysis was performed using $\mathrm{R}$ version 3.6.1 (27). Significance level was set at $p<0.05$.

Twelve of 148 participants had some responses missing on their PSI-SF $(<9 \%)$. Missing responses were imputed using multiple imputation. We created and analyzed 10 imputed datasets $(28,29)$. Missing values on household income (1\%) were also imputed.

\section{Results}

Table 1 outlines descriptive characteristics. The mean $( \pm$ SD) age of children was $11.4( \pm 3.1)$ months at baseline, and $37.2( \pm 1.7)$ months at outcome; $49 \%$ of children included in this study were male. Parents scored an average of $60.0 \pm 15.5$ on parenting stress, well below scores considered high. Approximately $2 \%$ of parenting stress percentile scores fell within the high or clinically significant range. Parents were relatively well educated and financially secure as $96 \%$ of mothers had a college/university degree, and $94 \%$ reported an annual household income $>\$ 60,000$.

A statistically significant correlation was identified between parenting stress and mental health problems (Pearson correlation coefficient $=0.44,95 \%$ CI $=0.29$ $0.56, p=0.001)$. Significant correlations between parenting stress and negative affect, as well as between both temperament traits and mental health problems, were also found. See Table 2.

Table 1 Descriptive Characteristics

\begin{tabular}{|c|c|}
\hline Characteristics & $\begin{array}{l}\text { All participants } \\
(n=148)\end{array}$ \\
\hline \multicolumn{2}{|l|}{ Age, mo, mean \pm SD (min-max) } \\
\hline Baseline & $11.4 \pm 3.1(0-16.0)$ \\
\hline Outcome & $37.2 \pm 1.7(36.0-47.0)$ \\
\hline Male, $n(\%)$ & $73(49.3)$ \\
\hline $\begin{array}{l}\text { Mental Health Problems }{ }^{a} \text {, } \\
\text { mean } \pm \text { SD (min-max })\end{array}$ & $8.8 \pm 4.4(1.0-26.0)$ \\
\hline $\begin{array}{l}\text { Parenting stress }{ }^{b}, \text { mean } \pm \\
\text { SD (min-max) }\end{array}$ & $60.0 \pm 15.5(36.0-105.0)$ \\
\hline \multicolumn{2}{|l|}{$\begin{array}{l}\text { Temperament }{ }^{c}, \text { mean } \pm S D \\
(\min -\max )\end{array}$} \\
\hline Negative affect & $3.7 \pm 0.9(1.8-6.1)$ \\
\hline Effortful control & $5.4 \pm 0.7(3.5-6.7)$ \\
\hline $\begin{array}{l}\text { Sleep duration }{ }^{d}, \text { mean } \pm \\
\text { SD (min-max) }\end{array}$ & $11.6 \pm 1.1(8.0-14.0)$ \\
\hline $\begin{array}{l}\text { Maternal education high } \\
\text { school or less, } \mathrm{n}(\%)\end{array}$ & $5(3.4)$ \\
\hline Household income $e^{\mathrm{e}}<\$ 60,000, \mathrm{n}(\%)$ & $7(4.7)$ \\
\hline
\end{tabular}

SD standard deviation

${ }^{a}$ Total difficulties score - preschool Strengths and Difficulties Questionnaire (P-SDQ)

${ }^{\mathrm{b}}$ Total stress score - Parent Stress Index Short Form (PSI-SF)

${ }^{c}$ Child Behavior Questionnaire - Very Short Form (CBQ-VSF)

${ }^{\mathrm{d}}$ Number of hours slept in a 24 -h period

${ }^{\mathrm{e}}$ Annual household income (dichotomized at 60,000 CAD)
After accounting for child age at baseline, sex, household income, and sleep duration (model 1), negative affect and effortful control (model 2), parenting stress during infancy (model 3) was associated with total mental health problems in children at 3 years $(\beta=0.35 ; 95 \%$ $\mathrm{CI}=0.20-0.49, p<0.001)$. Model 3 explained significant variance in the outcome (adjusted R-squared $=0.39, \mathrm{~F}(7$, $140)=14.35, p<0.001)$ and significantly more variance than Model 1 (adjusted R-squared $=0.06, F(4,143)=$ 3.67, $p=<0.01$ ) and Model 2 (adjusted R-squared $=0.29$, $\mathrm{F}(6,141)=11.46, p<0.001)$. See Table 3.

In addition, a one standard deviation increase in parenting stress during infancy was associated with twice the odds of the child being at high risk of total mental health difficulties at 3 years $(\mathrm{OR}=2.26,95 \% \mathrm{CI}=1.69$ 2.83, $p<0.01)$. See Table 4 .

\section{Discussion}

We found that stress in the parent-child system during infancy was associated with subsequent mental health problems in preschool-aged children. Indeed, while parenting stress during infancy is associated with negative affect, its contribution to preschool mental health problems is beyond that of temperament factors known to be linked. This finding expands our understanding of modifiable predictors during infancy and toddlerhood, and suggests that parenting stress is an important potential target for intervention (30).

Conceptually, the observed relationship between parentchild systems under stress and emotional and behavioral problems in children is well described. Parents under stress are less likely to be engaged, more irritable and distant with their young children (31). Particularly in the early years, positive bonding experiences and interactions between parent and child are fundamental for building competencies that support growth and development. A lack of early parental nurturance, parental negativity or over-reactivity can impact emotional and behavioral development in children, and have deleterious long-term consequences including, but not limited to, negative adjustment outcomes (e.g. social-emotional and peer difficulties), and increased risk for mental health and substance use problems as they grow older $(32,33)$.

In addition, it is important to highlight the bidirectional associations between parenting stress and child behavior. Stress can negatively affect parents' interpretations of child behaviors, shaping subsequent parent-child interactions, potentially reducing parental responsiveness and sensitivity towards children, thus, impacting child behavior (34, 35). While the associations are difficult to disentangle, it is also well established that excessive stress that hinders parents' abilities to appropriately manage their own moods and reactions can perpetuate ongoing difficulties for parents and their children (36). Finally, this relationship could 
Table 2 Correlation Matrix

\begin{tabular}{lllll}
\hline Variable & $\mathbf{1}$ & $\mathbf{2}$ & $\mathbf{3}$ & $\mathbf{4}$ \\
\hline 1. Mental health problems & 1.0 & $0.41^{*}$ & $-0.37^{*}$ & $0.44^{*}$ \\
2. Negative affect & $0.41^{*}$ & 1.0 & -0.10 & $0.38^{*}$ \\
3. Effortful control & $-0.37^{*}$ & -0.10 & 1.0 & -0.01 \\
4. Parenting stress & $0.44^{*}$ & $0.38^{*}$ & -0.01 & 1.0 \\
\hline${ }^{*} p<0.05$ & & & &
\end{tabular}

be reflective of genetic variants that affect both a vulnerability to experience stress in parents, and emotional and behavioral problems in their children (37).

To our knowledge, much of the existing research has been completed in clinical settings (e.g. parents have post-partum psychosis or children are experiencing psychiatric disorders); this study is novel as it is documenting the association between parenting stress during infancy and mental health problems in a typically developing population. The impact of early parenting stress reinforces that mental health interventions for children must regularly assess parental well-being and include programs to assist parents in managing parentingrelated stress in order to effectively benefit young children. In addition, regular assessment of parenting stress can support clinicians in identifying preschool children at higher risk of clinical mental health problems. Mental health interventions with parenting programs (aimed at improving parent-child interactions, managing parenting stress, and promoting mindful parenting) can be valuable contributions to early mental health management in families $(38,39)$. Some of these early interventions have identified improvements in child internalizing and externalizing behaviors, as well as reductions in parenting stress (40).
Table 4 Adjusted logistic regression for association between parenting stress and mental health problems in 3-year-old children $^{a}$

\begin{tabular}{|c|c|c|}
\hline Variable & Adjusted OR & $95 \% \mathrm{Cl}$ \\
\hline $\mathrm{Age}^{\mathrm{b}}$ & 0.91 & $0.77,1.04$ \\
\hline Sex, female & 0.96 & $0.02,1.94$ \\
\hline Household income ${ }^{c}$, low & 3.17 & $1.23,5.10$ \\
\hline Sleep duration & 0.99 & $0.45,1.52$ \\
\hline Negative affect & $1.67^{*}$ & $1.15,2.18$ \\
\hline Effortful Control & $0.44^{*}$ & $0.08,0.94$ \\
\hline Parenting stress & $2.26^{*}$ & $1.69,2.83$ \\
\hline
\end{tabular}

a adjusted for all other variables in Table

${ }^{\mathrm{b}} \mathrm{Age}$ at baseline

'Annual household income dichotomized at 60,000 CAD ( $>60,000=$ high)

$O R$ indicates Odds ratio, $\mathrm{Cl}$ indicates Confidence interval

${ }^{*} p<0.05$.

\section{Strengths and limitations}

A strength of this study was the prospective analysis of parenting stress during infancy, and subsequent assessment of mental health problems in typically developing 3year-old children. An additional strength of this study was controlling for several important covariates, such as temperament traits, sleep duration and sociodemographic characteristics. Due to our primary care setting, our study was limited by reliance on parent-report measures, which could have common method bias. Parenting stress can affect parents' perceptions of child behavior, and it is possible that parents who experience early parenting stress are more likely to perceive their preschool child's behavior as problematic. Future research could include measures completed by additional caregivers, as well as more intensive observational data collection such as clinical assessments. In addition, few families that participated in our study experience high levels of socioeconomic risk and are

Table 3 Hierarchical linear regression for association between parenting stress and mental health problems in 3-year-old children

\begin{tabular}{|c|c|c|c|c|c|c|}
\hline \multirow[t]{2}{*}{ Variable } & \multicolumn{2}{|l|}{ Model 1} & \multicolumn{2}{|l|}{ Model 2} & \multicolumn{2}{|l|}{ Model 3} \\
\hline & $\beta$ (log) & $95 \% \mathrm{Cl}$ & $\beta$ (log) & $95 \% \mathrm{Cl}$ & $\beta$ (log) & $95 \% \mathrm{Cl}$ \\
\hline $\mathrm{Age}^{\mathrm{a}}$ & -0.01 & $-0.06,0.04$ & -0.01 & $-0.06,0.03$ & -0.03 & $-0.07,0.01$ \\
\hline Sex, female & -0.28 & $-0.60,0.03$ & -0.16 & $-0.45,0.12$ & -0.25 & $-0.52,0.02$ \\
\hline Household income, low & $1.19^{*}$ & $0.45,1.94$ & $0.89 *$ & $0.24,1.55$ & 0.50 & $-0.13,1.14$ \\
\hline Sleep duration & 0.01 & $-0.15,0.17$ & -0.01 & $-0.15,0.13$ & -0.00 & $-0.13,0.13$ \\
\hline Negative affect & & & $0.34^{*}$ & $0.21,0.49$ & $0.23^{*}$ & $0.09,0.37$ \\
\hline Effortful control & & & $-0.31^{*}$ & $-0.46,-0.17$ & $-0.31^{*}$ & $-0.45,-0.18$ \\
\hline Parenting Stress & & & & & $0.35^{*}$ & $0.20,0.49$ \\
\hline Adjusted $R^{b}$ & $0.06^{*}$ & & $0.29 *$ & & $0.39 *$ & \\
\hline Model F-statistic (df) & $3.67(4,143)$ & & $11.46(6,141)$ & & $14.35(7,140)$ & \\
\hline Change in F-statistic ( $p$-value) & 0.007 & & $<0.001$ & & $<0.001$ & \\
\hline
\end{tabular}

$\mathrm{Cl}$ indicates Confidence interval

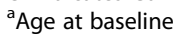

${ }^{\mathrm{b}}$ Annual household income dichotomized at 60,000 CAD $(\geq 60,000=$ high $)$

${ }^{*} p<0.05$. 
largely of middle-higher socio-economic status. Therefore, the results may not be generalizable to less-advantaged populations. Similarly, most of the reports of parenting stress measured in our study are considered typical. Yet, the relative lack of financial stressors and clinically significant parenting stress strengthens the importance of our findings - even in relatively affluent families, and among parents experiencing typical parenting stress, early parenting stress is associated with child mental health outcomes in preschool years.

\section{Conclusion}

Mental health problems in children emerge early and can have adverse and long-lasting impact on social, emotional and behavioral outcomes. This study highlights the role of early parenting stress as a risk factor for mental health problems in preschool-aged children. Our initial findings support further exploration of the relationship among parenting stress, child temperament and the emergence of mental health problems in early childhood. Study findings also underline the importance of identifying parents experiencing stress to help ameliorate mental health problems in preschool-aged children.

\section{Abbreviations}

P-SDQ: Preschool Strengths and Difficulties Questionnaire; PSI-SF: Parent Stress Index Short Form; CBQ-VSF: Child Behavior Questionnaire - Very Short Form

\section{Acknowledgements}

The authors thank all participating families for their time and involvement in TARGet Kids! and are grateful to all practitioners who are currently involved in the research network.

\section{Ethics and consent to participate}

The TARGet Kids! research platform has been approved by the Research Ethics Boards at the Hospital for Sick Children and St. Michael's Hospital, Toronto, Ontario, Canada. Informed written consent was obtained from all study participants. Written consent was obtained by parents of all participating children.

\section{Authors' contributions}

$\mathrm{NH}$ conceptualized and designed the study, conducted the analysis and interpretation of data, and drafted the manuscript. KTC and AC conceptualized and designed the study, assisted in interpretation of data, and revised the manuscript. CSB and JLM designed the study, assisted in acquisition and interpretation of data, and revised the manuscript. CMB and PZ designed the study, assisted in interpretation of data, and revised the manuscript. CSB and JLM lead the TARGet Kids! research program. All authors read and approved the final manuscript, and agree to be accountable for all aspects of the work.

\section{Funding}

The authors acknowledge the support of the Margaret and Wallace McCain Centre for Child, Youth and Family Mental Health at the Centre for Addiction and Mental Health (CAMH). The funding agency had no role in the design, collection, analysis or interpretation of the results of this study or in the preparation, review, or approval of the manuscript.

\section{Availability of data and materials}

The datasets used and/or analyzed during the current study are available upon reasonable request by contacting www.targetkids.ca/contact-us/.
Consent for publication

Not applicable.

\section{Competing interests}

The authors declare no competing interests.

\section{Author details}

${ }^{1}$ Department of Psychiatry, Hospital for Sick Children, Toronto, ON, Canada. ${ }^{2}$ Division of Pediatric Medicine and the Paediatric Outcomes Research Team (PORT), Hospital for Sick Children, Toronto, ON, Canada. ${ }^{3}$ Child Health Evaluative Sciences, SickKids Research Institute, Toronto, ON, Canada. ${ }^{4}$ Department of Pediatrics, Faculty of Medicine, University of Toronto, Toronto, ON, Canada. ${ }^{5}$ Institute of Health Policy Management and Evaluation, University of Toronto, Toronto, ON, Canada. ${ }^{6}$ Joannah \& Brian Lawson Centre for Child Nutrition, Department of Nutritional Sciences, University of Toronto, Toronto, ON, Canada. 'Women's College Research Institute, Women's College Hospital, Toronto, ON, Canada. ${ }^{8}$ The Centre for Urban Health Solutions, Li Ka Shing Knowledge Institute of St. Michael's Hospital, Toronto, ON, Canada.

${ }^{9}$ Department of Pediatrics, St. Michael's Hospital, Toronto, ON, Canada.

${ }^{10}$ Department of Psychiatry, University of Toronto, Toronto, ON, Canada.

${ }^{11}$ Centre for Addiction and Mental Health, Toronto, ON, Canada.

Received: 15 April 2020 Accepted: 9 November 2020

Published online: 16 November 2020

\section{References}

1. Skokauskas N, Fung D, Flaherty LT, von Klitzing K, Pūras D, Servili C, et al. Shaping the future of child and adolescent psychiatry. Child Adolesc Psychiatry Ment Health. 2019 Apr;11:13-9.

2. Kerker BD, Zhang J, Nadeem E, Stein RE, Hurlburt MS, Heneghan A, et al. Adverse childhood experiences and mental health, chronic medical conditions, and development in young children. Acad Pediatr. 2015;15(5):510-7.

3. Carneiro A, Dias P, Soares I. Risk factors for internalizing and externalizing problems in the preschool years: systematic literature review based on the child behavior checklist 11/2-5. J Child Fam Stud. 2016;25(10):2941-53.

4. Bufferd SJ, Dougherty LR, Carlson GA, Rose S, Klein DN. Psychiatric disorders in preschoolers: continuity from ages 3 to 6. Am J Psychiatry. 2012 Nov; 169(11):1157-64

5. Côté SM, Boivin M, Liu X, Nagin DS, Zoccolillo M, Tremblay RE. Depression and anxiety symptoms: onset, developmental course and risk factors during early childhood. J Child Psychol Psychiatry. 2009 Oct;50(10):1201-8.

6. Weijers D, van Steensel FJA, Bögels SM. Associations between psychopathology in mothers, fathers and their children: a structural modeling approach. J Child Fam Stud. 2018 Mar;27(6):1992-2003.

7. Pinquart M. Associations of parenting dimensions and styles with externalizing problems of children and adolescents: an updated metaanalysis. Dev Psychol. 2017 May:53(5):873-932.

8. Mackler JS, Kelleher RT, Shanahan L, Calkins SD, Keane SP, O'Brien M. Parenting stress, parental reactions, and externalizing behavior from ages 4 to 10. J Marriage Fam. 2015 Apr;77(2):388-406.

9. Barroso NE, Mendez L, Graziano PA, Bagner DM. Parenting stress through the lens of different clinical groups: a systematic review \& meta-analysis. J Abnorm Child Psychol. 2018 Apr;46(3):449-61.

10. Theule J, Wiener J, Tannock R, Jenkins JM. Parenting stress in families of children with ADHD: a meta-analysis. J Emot Behav Disord. 2013 Mar;21:317. https://doi.org/10.1177/1063426610387433.

11. Postorino V, Gillespie S, Lecavalier L, Smith T, Johnson C, Swiezy N, et al. Clinical correlates of parenting stress in children with autism spectrum disorder and serious behavioral problems. J Child Fam Stud. 2019 Jun;28: 2069-77. https://doi.org/10.1007/s10826-019-01423-7.

12. Rothbart MK, Ahadi SA, Evans DE. Temperament and personality: origins and outcomes. J Pers Soc Psychol. 2000 Jan;78(1):122-35.

13. Lahey BB, Van Hulle CA, Keenan K, Tathouz PJ, D'Onofrio BM, Rodgers $J$, et al. Temperament and parenting during the first year of life predict future child conduct problems. J Abnorm Child Psychol. 2008 Nov;36(8):1139-58.

14. Eisenberg N, Valiente C, Spinrad TL, Cumerland A, Liew J, Reiser M, et al Longitudinal relations of children's effortful control, impulsivity, and negative emotionality to their externalizing, internalizing, and co-occurring behavior problems. Dev Psychol. 2009 Nov;45(4):988-1008. 
15. Wichstrøm L, Penelo E, Rensvik Viddal K, de la Osa N, Ezpeleta L. Explaining the relationship between temperament and symptoms of psychiatric disorders from preschool to middle childhood: hybrid fixed and random effects models of Norwegian and Spanish children. J Child Psychol Psychiatry. 2018 Mar;59(3):285-95.

16. Reynaud E, Vecchierini MF, Heude B, Charles MA, Plancoulaine S. Sleep and its relation to cognition and behaviour in preschool-aged children of the general population: a systematic review. J Sleep Res. 2018 Jun; 27(3):e12636.

17. Cremone A, de Jong DM, Kurdziel LBF, Desrochers P, Sayer A, LeBourgeois $M$, et al. Sleep tight, act right: negative affect, sleep and behavior problems during early childhood. Child Dev. 2018 Mar;89(2):e42-59.

18. Sinai $D$, Tikotzky L. Infant sleep, parental sleep and parenting stress in families of mothers on maternity leave and in families of working mothers. Infant Behav Dev. 2012 Apr;35(2):179-86.

19. Carsley S, Borkhoff CM, Maguire JL, Birken CS, Khovratovich M, McCrindle B, et al. Cohort profile: the applied research Group for Kids (TARGet kids!). Int J Epidemiol. 2015 Jun;44(3):776-88.

20. Goodman R. The strengths and difficulties questionnaire: a research note. J Child Psychol Psychiatry. 1997;38(5):581-6.

21. Abidin RR. The parenting stress index-short form. Charlottesville, VA: Pediatric Psychology Press; 1990.

22. D'Souza S, Waldie KE, Peterson ER, Underwood L, Morton SM. Psychometric properties and normative data for the preschool strengths and difficulties questionnaire in two-year-old children. J Abnorm Child Psychol. 2017 Feb; 45(2):345-57.

23. Goodman R. Psychometric properties of the strengths and difficulties questionnaire. J Am Acad Child Adolesc Psychiatry. 2001 Nov:40:133745.

24. Maurice-Stam H, Haverman L, Splinter A, van Oers HA, Schepers SA, Grootenhuis MA. Dutch norms for the strengths and difficulties questionnaire (SDQ) - parent form for children aged 2-18 years. Health Qual Life Outcomes. 2018;16(123). https://doi.org/10.1186/s12955-018-0948-1.

25. Putnam SP, Rothbart MK. Development of short and very short forms of the Children's behavior questionnaire. J Pers Assess. 2006 Aug;87(1):102-12.

26. Champely S. Pwr: Basic functions for power analysis. R package version 1.2.2. 2018. https://CRAN.R-project.org/package=pwr.

27. R Core Team. R: A language and environment for statistical computing. Vienna, Austria: R Foundation for statistical computing; 2019. https:/www.R-project.org/.

28. van Buuren S, Groothuis-Oudshoorn K. Mice: multivariate imputation by chained equations in R. J Stat Softw. 2011;45(3):1-67.

29. Pedersen AB, Mikkelsen EM, Cronin-Fenton D, Kristensen NR, Pham TM, Pedersen $L$, et al. Missing data and multiple imputation in clinical epidemiological research. Clin Epidemiol. 2017 Mar;9:157-66.

30. Thomas R, Abell B, Webb HJ, et al. Parent-child interaction therapy: a metaanalysis. Pediatrics. 2017;140(3):e20170352.

31. Anthony L, Anthony B, Glanville D, Naiman D, Waanders C, Shaffer S. The relationships between parenting stress, parenting behavior and preschoolers' social competence and behavior problems in the classroom. Infant Child Dev. 2005;14:133-54.

32. Crnic KA, Gaze C, Hoffman C. Cumulative parenting stress across the preschool period: relations to maternal parenting and child behavior at age 5. Infant Child Dev. 2005 May;14:117-32. https://doi.org/10.1002/icd. 384.

33. Hintsanen $M$, Gluschkoff $K$, Dobewall $H$, Cloninger $C R$, Keltner $D$, Saarinen $A$, et al. Parent-child-relationship quality predicts offspring dispositional compassion in adulthood: a prospective follow-up study over three decades. Dev Psychol. 2019 Jan;55(1):216-25.

34. Webster-Stratton C. Stress: a potential disruptor of parent perceptions and family interactions. J Clin Child Psychol. 2010s:302-12. https://doi.org/10. 1207/s15374424jccp1904_2.

35. Unternaehrer E, Cost KT, Bouvette-Turcot AA, Gaudreau H, Massicotte R, Dhir SK, et al. Dissecting maternal care: Patterns of maternal parenting in a prospective cohort study. J. Neuroendocrinol. 2019;31:9.

36. Achtergarde S, Postert C, Wessing I, Romer G, Müller JM. Parenting and child mental health: influences of parent personality, child temperament, and their interaction. TFJ. 2015;23(2):167-79. https://doi.org/10.1177/ 1066480714564316.

37. Mann CC. Behavioral genetics in transition: a mass of evidence - animal and human - shows that genes influence behavior. Science. 1994s;264(5166): 1686-9. https://doi.org/10.1126/science.8209246.
38. Leijten P, Shaw DS, Gardner F, Wilson MN, Matthys W, Dishion TJ. The family check-up and service use in high-risk families of young children: a prevention strategy with a bridge to community-based treatment. Prev Sci. 2015 Apr;16(3):397-406. https://doi.org/10.1007/s11121-0140479-x.

39. Mendez LR, Ogg J, Loker T, Fefer S. Including parents in the continuum of school-based mental health services: a review of intervention program research from 1995 to 2010. J Appl Sch Psychol. 2013 Feb;29(1):1-36.

40. Kaarensen PI, Ronning JA, Ulvund SE, Dahl LB. A randomized, controlled tria of the effectiveness of an early-intervention program in reducing parenting stress after preterm birth. Pediatrics. 2006 Jul;118(1):e9-e19.

\section{Publisher's Note}

Springer Nature remains neutral with regard to jurisdictional claims in published maps and institutional affiliations.
Ready to submit your research? Choose BMC and benefit from:

- fast, convenient online submission

- thorough peer review by experienced researchers in your field

- rapid publication on acceptance

- support for research data, including large and complex data types

- gold Open Access which fosters wider collaboration and increased citations

- maximum visibility for your research: over $100 \mathrm{M}$ website views per year

At BMC, research is always in progress.

Learn more biomedcentral.com/submissions 